\title{
Low molecular mass chitosan as carrier for a hydrodynamically balanced system for sustained delivery of ciprofloxacin hydrochloride
}

\author{
ANURAG VERMA ${ }^{1 *}$ \\ ASHOK K. BANSAL \\ AMITAVA GHOSH ${ }^{1}$ \\ JAYANTA K. PANDIT ${ }^{2}$ \\ ${ }^{1}$ Department of Pharmaceutics \\ College of Pharmacy, IFTM \\ Moradabad-244001, India \\ 2 Department of Pharmaceutics \\ Institute of Technology, Banaras \\ Hindu University, Varanasi, India
}

Accepted April 3, 2012

\begin{abstract}
Chitosan has become a focus of major interest in recent years due to its excellent biocompatibility, biodegradability and non-toxicity. Although this material has already been extensively investigated in the design of different types of drug delivery systems, it is still little explored for stomach specific drug delivery systems. The objective of the present investigation was to explore the potential of low molecular mass chitosan (LMCH) as carrier for a hydrodynamically balanced system (HBS) for sustained delivery of water soluble drug ciprofloxacin hydrochloride $(\mathrm{CP})$. Various formulations were prepared by physical blending of drug and polymer(s) in varying ratios followed by encapsulation into hard gelatin capsules. All the formulations remained buoyant in $0.1 \mathrm{~mol} \mathrm{~L}^{-1} \mathrm{HCl}$ $(\mathrm{pH}$ 1.2) throughout the experiment. Effect of addition of xanthan gum (XG) or ethyl cellulose (EC) on drug release was also investigated. Zero order drug release was obtained from the formulations containing $\mathrm{LMCH}$ alone or in combination with $X G$, and in one instance also with EC. Our results suggest that LMCH alone or in combination with $X G$ is an excellent material for stomach specific sustained delivery of $\mathrm{CP}$ from hydrodynamically balanced single unit capsules.
\end{abstract}

Keywords: low molecular mass chitosan, xanthan gum, ciprofloxacin, hydrodynamically balanced capsules, stomach specific release

An important criterion in the selection of polymers as carriers for drug delivery is their metabolic fate in the body or biodegradation. Researchers have strived to engineer or discover polymeric materials. Practically limitless are combinations of these materials to regulate the physical and chemical properties of drug delivery systems, such as their permeability, environmental response, surface functionality, biodegradability, and biorecognition sites to produce »intelligent» drug delivery systems. Of these, chitosan has re-

\footnotetext{
* Correspondence; e-mail: anuragverma_iftm@yahoo.co.in
} 
A. Verma et al.: Low molecular mass chitosan as carrier for a hydrodynamically balanced system for sustained delivery of ciprofloxacin hydrochloride, Acta Pharm. 62 (2012) 237-250.

ceived a great deal of attention due to its biocompatibility and low toxicity (1). Chitosan has been extensively investigated in the design of many different types of drug carriers for various administration routes such as oral, buccal, nasal, transdermal, parenteral, vaginal, cervical, intrauterine and rectal as well as in slow-release floating or gastroretentive drug delivery systems (2). Chitosan could be ideal for use in formulations intended to release drugs slowly in the stomach, since the gel formation by cationic chitosan, is pronounced at acidic $\mathrm{pH}$ levels, results in marked retardant effects on drug release (3). In previous studies of pharmaceutical formulations, little attention has been paid to the effect of molecular mass of chitosan. Yassin et al. (4) prepared an extended release gastroretentive mutiparticulate delivery system for verapamil by its incorporation into hydrogel beads made of medium molecular mass chitosan. Prepared beads showed slow release as well as excellent buoyancy. Most of the other studies were carried out using commercially produced chitosan (5). Considering the fact that very little work has been carried out to investigate the applicability of $\mathrm{LMCH}$, the authors have decided to undertake the present work, first to check the applicability of $\mathrm{LMCH}$ in the design of single-unit hydrodynamically balanced capsule formulations using $\mathrm{CP}$ as a model drug and secondly, its role alone or in combination with other polymers in sustaining drug release from the prepared system.

\section{EXPERIMENTAL}

\section{Materials}

Ciprofloxacin hydrochloride (CP) was obtained as a gift sample from Ranbaxy Research Laboratories, India. Low molecular mass chitosan (LMCH) was procured from Sigma Aldrich Brookfield viscosity $20.00 \mathrm{cps}$ of $1 \%$ in $1 \%$ acetic acid, degree of deacetylation (DD) $>80 \%$, molecular mass $=150,000$, as supplied by the manufacturer. Xanthan gum (XG) and ethyl cellulose (EC) were procured from the Central Drug House, India. All other chemicals used were of analytical grade.

\section{Methods}

Drug-excipient and excipient-excipient interaction studies. - Fourier transform infrared spectroscopy (FTIR) and differential scanning calorimetry (DSC) were employed to study drug-excipient and excipient-excipient interactions. FTIR spectra were recorded for LMCH, XG, CP and their physical mixtures using a FTIR facility (Shimadju, 8400S, Japan). Samples were prepared in $\mathrm{KBr}$ disks (2 $\mathrm{mg}$ sample in $200 \mathrm{mg} \mathrm{KBr}$ ). The scanning range was $400-4000 \mathrm{~cm}^{-1}$ and the resolution was $2 \mathrm{~cm}^{-1}$.

For DSC (Universal V4.5A TA instrument, New Castle, USA) studies, approximately 5-mg samples of $\mathrm{LMCH}, \mathrm{XG}, \mathrm{CP}$ and their physical mixtures were placed individually on a standard aluminium pan and heated to $400{ }^{\circ} \mathrm{C}$ (at a rate of $10{ }^{\circ} \mathrm{C} \mathrm{min}-1$ ). Characteristic peaks and heat of melting were recorded.

Stability of ciprofloxacin hydrochloride in $\mathrm{HCl}$. - Stability of CP in 0.1 and $0.01 \mathrm{~mol} \mathrm{~L}^{-1}$ ( $\mathrm{pH} 1.2$ and $\mathrm{pH} 2.0$, respectively) $\mathrm{HCl}$ was determined in order to ascertain whether the drug would remain stable throughout the period of drug release. Briefly, the drug was 
A. Verma et al: Low molecular mass chitosan as carrier for a hydrodynamically balanced system for sustained delivery of ciprofloxacin hydrochloride, Acta Pharm. 62 (2012) 237-250.

dissolved in either 0.1 or $0.01 \mathrm{~mol} \mathrm{~L}^{-1} \mathrm{HCl}$. The temperature of the system was maintained at $37 \pm 0.5^{\circ} \mathrm{C}$. One $\mathrm{mL}$ aliquot was withdrawn every hour and replenished with fresh dissolution medium. The samples so withdrawn were suitably diluted and absorbances of the solutions were measured at $276 \mathrm{~nm}$ ultraviolet (spectrophotometer Shimadzu 1800).

Preparation of hydrodynamically balanced capsules. - Single-unit hydrodynamically balanced capsule formulations, whose composition is shown in Table I, were prepared by physically blending $\mathrm{CP}$ and $\mathrm{LMCH}$ alone or in combination with $\mathrm{XG}$ or EC in a double-cone blender for $15 \mathrm{~min}$, followed by encapsulation in colorless transparent hard gelatin capsules (6).

Determination of drug concentration in formulations. - Drug concentration in each formulation was determined in triplicate by emptying each formulation separately as completely as possible into $0.1 \mathrm{~mol} \mathrm{~L}^{-1} \mathrm{HCl}$ at $37 \pm 0.5^{\circ} \mathrm{C}$, followed by stirring for one hour at $500 \mathrm{rpm}$. The solution was filtered through a $0.45-\mu \mathrm{m}$ membrane filter, diluted suitably and absorbance of the resultant solution was measured at $276 \mathrm{~nm}$.

In vitro buoyancy studies. - The prepared capsule formulations were immersed in $900 \mathrm{~mL}$ of $0.1 \mathrm{~mol} \mathrm{~L}^{-1} \mathrm{HCl}$ in a USP paddle type apparatus (7) at $50 \mathrm{rpm}$. The time during which the formulations remained buoyant was observed and was taken as the floating time.

Viscosity measurements. - The purpose of viscosity measurement studies was to study the effect of gelled polymeric matrix on CP release. Further, viscosity measurement studies are also useful to study the possibility of polyelectrolyte complex formation between oppositely charged macromolecules in the solution state.

The viscosity of sols (drug-free) prepared in $0.1 \mathrm{~mol} \mathrm{~L}^{-1} \mathrm{HCl}$ was determined at $37 \pm 1{ }^{\circ} \mathrm{C}$ with a Brookfield cone and plate rheometer with cone angle $0.8^{\circ}$ (DV-III ULTRA, Brookfield Engineering Laboratories, USA) using spindle $\mathrm{cp} 40$. Evaluations were conducted in triplicate.

Table I. Composition of HBS capsules containing ciprofloxacin hydrochloride $(\mathrm{CP})$ with and without release modifiers

\begin{tabular}{ccccc}
\hline Formulation code & LMCH $(\mathrm{mg})$ & XG $(\mathrm{mg})$ & EC $(\mathrm{mg})$ & $\mathrm{CP}(\mathrm{mg})^{\mathrm{a}}$ \\
\hline F1 & 100 & & & 116 \\
F2 & 100 & & & 174 \\
F3 & 100 & 10 & & 116 \\
F4 & 100 & 20 & & 116 \\
F5 & 100 & 30 & 50 & 116 \\
F6 & 100 & & 100 & 174 \\
F7 & 50 & & 50 & 116 \\
F8 & & & & 116 \\
F9 & 100 & & & 174 \\
\hline
\end{tabular}

a Concentration of CP in formulations range 47.2-61.3\%. 
A. Verma et al.: Low molecular mass chitosan as carrier for a hydrodynamically balanced system for sustained delivery of ciprofloxacin hydrochloride, Acta Pharm. 62 (2012) 237-250.

Drug release and drug release mechanism. - Based on the buoyancy studies, formulations showing good floatation were subjected to in vitro release studies performed in 900 $\mathrm{mL} 0.1 \mathrm{~mol} \mathrm{~L}^{-1} \mathrm{HCl}\left(\mathrm{pH} 1.2,37 \pm 0.5^{\circ} \mathrm{C}\right)$ using the USP 27 paddle type apparatus $(7)$ at $50 \mathrm{rpm}$. At predetermined intervals, 1-mL aliquots were withdrawn and replenished with an equal volume of fresh dissolution medium. Withdrawn samples were suitably diluted with $0.1 \mathrm{~mol} \mathrm{~L}^{-1} \mathrm{HCl}$ and analyzed at $276 \mathrm{~nm}$. Experiments were preformed in triplicate.

In order to describe the kinetics of CP release from hydrodynamically balanced capsule formulations, various equations were used, such as the zero-order rate equation, which describes the systems where the release rate is independent of the concentration of the dissolved species. The first-order equation describes the release from systems where dissolution rate is dependent on the concentration of the dissolving species (8). In vitro data were also fitted to Higuchi's square root model (9) which describes the release from systems where the solid drug is dispersed in an insoluble matrix and the rate of drug release is related to the rate of drug diffusion. Release of a drug from an insoluble matrix is the square root of a time-dependent process based on Fickian diffusion:

$$
Q_{\mathrm{t}}=k_{\mathrm{H}} t^{1 / 2}
$$

were $Q_{\mathrm{t}}$ is the amount of drug released in time $t$ and $k_{\mathrm{H}}$ is the release rate conatant for the Higuchi model.

Under some experimental situations, the release mechanism deviates from Fick's equation, following an anomalous behavior (non-Fickian release). In these cases a more generic equation can be used. Korsmeyer et al. (10) developed a simple, semi-empirical model, relating exponentially the drug release to the elapsed time.

$$
M_{t} / M_{\infty}=k t^{n}
$$

where $M_{t} / M_{\infty}$ is the fraction of drug released at time $t ; k$ is a constant reflecting the design variables of the system and $n$, the release exponent, is a parameter that depends on the release mechanism and is thus used to characterize it. If the $n$ value is 0.5 or less, the release mechanism follows Fickian diffusion, and values $0.5<n<1$ for mass transfer follow a non-Fickian model (anomalous transport). Drug release follows zero-order drug release and case-II transport if the $n$ value is 1 . For the values of $n$ higher than 1 , the mechanism of drug release is regarded as super case-II transport. This model is used to analyze the release from pharmaceutical polymeric dosage forms when the release mechanism is not well known or when more than one type of release phenomena are involved.

\section{Statistical analysis}

The differences in average data were compared by simple analysis of variance (one-way analysis of variance) or Student's $t$ test (SigmaPlot $\left.{ }^{\circledR} 11\right)$. 
A. Verma et al: Low molecular mass chitosan as carrier for a hydrodynamically balanced system for sustained delivery of ciprofloxacin hydrochloride, Acta Pharm. 62 (2012) 237-250.

\section{RESULTS AND DISCUSSION}

\section{Solid state interaction studies}

\section{FTIR characterization and thermal characterization}

The FTIR spectra of LMCH (Fig. 1a) exhibited absorption band at 1628, 1380 and $1320 \mathrm{~cm}^{-1}$ due to amide I, II and III. Absorption bands at 3371 and $2924 \mathrm{~cm}^{-1}$ are due to the hydroxyl stretch and C-H stretch. The FTIR spectra of XG showed major absorption bands at 1620 and $1419 \mathrm{~cm}^{-1}$ due to asymmetric and symmetric vibrations of $\mathrm{COO}^{-}$in pyruvate and glucuronate groups (Fig. 1b). The FTIR spectra of the physical mixture of LMCH and XG (LMCH:XG 3.33:1, without CP) showed slight shifting in absorption
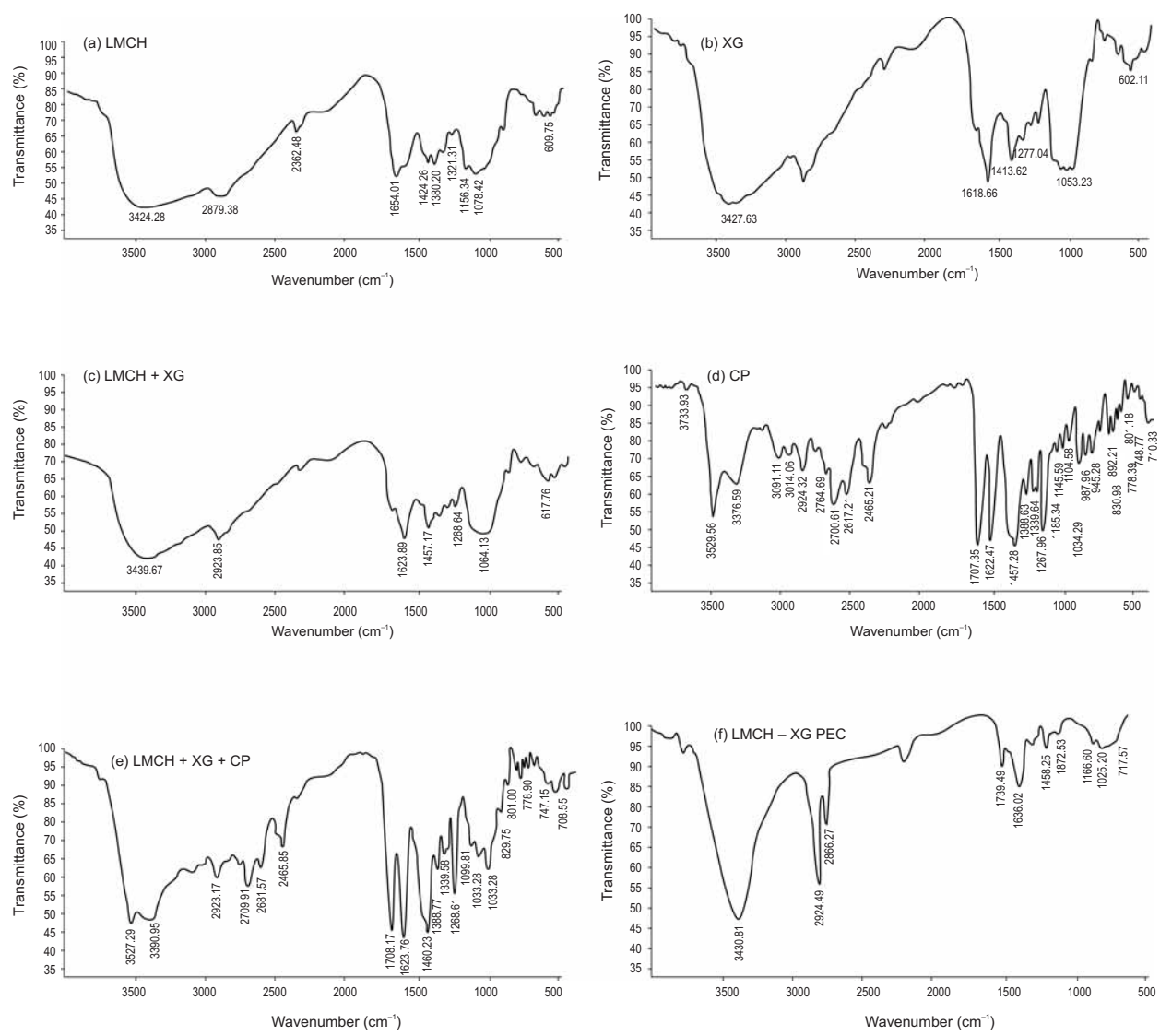

Fig. 1. FTIR spectra of: a) $L M C H, b) X G, c) L M C H+X G$ physical mixture, d) CP, e) $L M C H+X G+$ $\mathrm{CP}$ physical mixture and f) dried $\mathrm{LMCH}+\mathrm{XG}$ matrix after 60 min gelation in $0.1 \mathrm{~mol} \mathrm{~L}^{-1} \mathrm{HCl}$. 
A. Verma et al:: Low molecular mass chitosan as carrier for a hydrodynamically balanced system for sustained delivery of ciprofloxacin hydrochloride, Acta Pharm. 62 (2012) 237-250.

bands; band at $1628 \mathrm{~cm}^{-1}$ in LMCH shifted to $1612 \mathrm{~cm}^{-1}$, which suggests a slight change in the environment of $\mathrm{C}=\mathrm{O}$ and amide I (Fig. 1c). The FTIR spectra of pure CP (Fig. 1d) showed absorption bands at 3525, 3379, 3086, 3024 and $2923 \mathrm{~cm}^{-1}$ corresponding to O-H stretch of the carboxylic group, $\mathrm{N}-\mathrm{H}$ stretch, $\mathrm{C}-\mathrm{H}$ stretch of the aromatic group and $\mathrm{C}-\mathrm{H}$ stretch of the $\mathrm{CH}_{2}$ group, respectively. Further, absorption bands at 1705 and $1620 \mathrm{~cm}^{-1}$ are characteristic of $\mathrm{C}=\mathrm{O}$ stretch of carboxylic acid and ketone group. On the other hand,
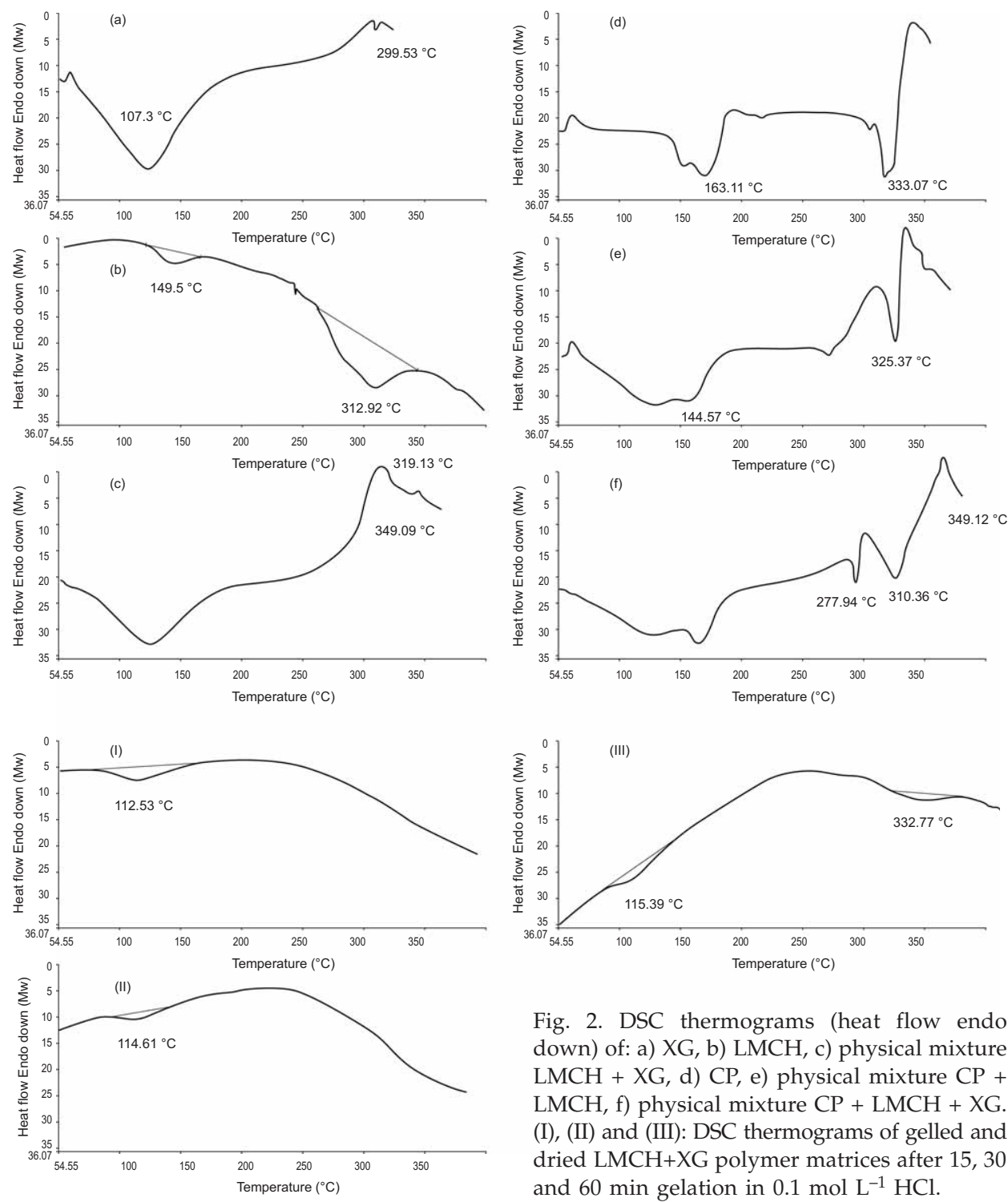

Fig. 2. DSC thermograms (heat flow endo down) of: a) XG, b) LMCH, c) physical mixture $\mathrm{LMCH}+\mathrm{XG}, \mathrm{d}) \mathrm{CP}, \mathrm{e})$ physical mixture $\mathrm{CP}+$ $\mathrm{LMCH}, \mathrm{f})$ physical mixture $\mathrm{CP}+\mathrm{LMCH}+\mathrm{XG}$. (I), (II) and (III): DSC thermograms of gelled and dried $\mathrm{LMCH}+\mathrm{XG}$ polymer matrices after 15,30 and $60 \mathrm{~min}$ gelation in $0.1 \mathrm{~mol} \mathrm{~L}^{-1} \mathrm{HCl}$. 
A. Verma et al.: Low molecular mass chitosan as carrier for a hydrodynamically balanced system for sustained delivery of ciprofloxacin hydrochloride, Acta Pharm. 62 (2012) 237-250.

FTIR spectra of the physical mixture of CP, LMCH and XG (LMCH:XG ratio 3.33:1, with $\mathrm{CP}$ ) showed no interaction with the drug (Fig. 1e), as major peaks of $\mathrm{CP}$ were found intact in the spectra.

DSC is used for determination of the melting point, changes in crystallinity and to detect any possible interaction between the drug and carrier. DSC thermograms for the polymers, drug and their physical mixtures are shown in Fig. 2.

The DSC thermogram of XG has two endothermic peaks (Fig. 2a): a broad endothermic peak at $107^{\circ} \mathrm{C}$ may represent loss of water, whereas the weak peak at $299^{\circ} \mathrm{C}$ could be attributed to the melting of XG. The DSC thermogram of LMCH showed two endothermic peaks (Fig. 2b): the peak at $149.5{ }^{\circ} \mathrm{C}$ represents the glass transition temperature of $\mathrm{LMCH}$, whereas the broad endothermic peak at $312{ }^{\circ} \mathrm{C}$ may be attributed to the very slow melting of $\mathrm{LMCH}$.

The DSC thermogram of a physical mixture (same ratio as that used in the formulation F5, but without CP) of LMCH and XG (3.33:1) showed two exothermic peaks at 319 and $349{ }^{\circ} \mathrm{C}$ (Fig. 2c). These peaks could be attributed to the degradation of LMCH and $\mathrm{XG}$ rather than to interaction between the polymers.

The DSC thermogram of CP showed two endothermic peaks at 163 and $333{ }^{\circ} \mathrm{C}$ attributed to loss of water and melting of CP (Fig. 2d). The DSC thermogram of physical mixture of $\mathrm{CP}$ and $\mathrm{LMCH}$ showed two endothermic peaks at 144 and $325^{\circ} \mathrm{C}$ attributed to the glass transition temperature of the polymer and melting of $\mathrm{CP}$ (Fig. 2e). Although the melting endotherm of $\mathrm{CP}$ was slightly shifted to lower temperature, it should not be considered as interaction. On the other hand, the DSC thermogram of the physical mixture of $\mathrm{CP}, \mathrm{LMCH}$ and $\mathrm{XG}$ (F5) showed two endotherms and one exotherm (Fig. 2f). The first endothermic peak at $277^{\circ} \mathrm{C}$ could be attributed to the melting of $X G$, whereas the second endothermic peak at $310{ }^{\circ} \mathrm{C}$ could be due to the melting of $\mathrm{CP}$. The exothermic peak at $349^{\circ} \mathrm{C}$ seems to be a superimposed one and could be attributed to degradation of both $\mathrm{CP}$ and XG.

\section{Liquid state interaction studies}

$\mathrm{LMCH}$ has many amino groups in its structure ready to be protonated when exposed to acidic fluids (generally $\mathrm{HCl}$ or acetic acid). Further, $\mathrm{LMCH}$ is also reported to form a polyelectrolyte complex (PEC) with anionic compounds (11). Although the data from solid state interaction studies did not reveal interaction between LMCH and XG, there is a strong possibility that such interaction might occur when the formulation is exposed to $0.1 \mathrm{~mol} \mathrm{~L}^{-1} \mathrm{HCl}$ during dissolution studies. Therefore, it is highly desirable to study the interaction $\mathrm{LMCH}$ and $\mathrm{XG}$ when the formulation is at various stages of gel formation due to penetration of dissolution medium.

DSC thermograms of samples (LMCH:XG 3.33:1) taken after a period of 15 (beginning of gel formation at the outer surface of polymer matrix), 30 (gel formation at the outer surface) and $60 \mathrm{~min}$ (penetration of dissolution medium into the core of polymer matrix) of exposure to dissolution medium were recorded. The DSC thermograms of samples taken at 15 and 30 min interval revealed only a single endotherm at 112 and $114{ }^{\circ} \mathrm{C}$, respectively (Figs. 2I and II), whereas thermogram of the sample taken at $60 \mathrm{~min}$ showed two endotherms at 115 and cca $333{ }^{\circ} \mathrm{C}$, respectively (Fig. 2III). The broad endotherm at $333{ }^{\circ} \mathrm{C}$ may be the indication of the polyelectrolyte complex formation. To further con- 
A. Verma et al.: Low molecular mass chitosan as carrier for a hydrodynamically balanced system for sustained delivery of ciprofloxacin hydrochloride, Acta Pharm. 62 (2012) 237-250.

firm PEC formation, the 60 min sample (LMCH:XG 3.33:1) was subjected to FTIR analysis. The FTIR spectrum of the above mentioned gelled sample (Fig. 1f) showed new bands at 1742 and $1544 \mathrm{~cm}^{-1}$. The appearance of these bands in the spectrum of gelled sample (LMCH:XG 3.33:1, $60 \mathrm{~min}$ ) could be taken as an evidence of change in the environment of the amine group of $\mathrm{LMCH}$ through its interaction with the carboxylate group on XG.

\section{Stability of ciprofloxacin hydrochloride in $\mathrm{HCl}$}

CP showed significant $(p<0.05)$ degradation at both $\mathrm{pHs}(\mathrm{pH} 1.2$ and 2.0) at all concentrations. Drug degradation was also found to be concentration dependent.

At concentration $1 \mathrm{mg} \mathrm{mL}^{-1}, 2 \%$ of the $\mathrm{CP}$ degraded after 12 hours at both $\mathrm{pHs}$, whereas it was $6 \%$ at concentrations 2 and $3 \mathrm{mg} \mathrm{mL}^{-1}$. At pH 2.0, degradation was $2.5 \%$ ( $2 \mathrm{mg} \mathrm{mL}^{-1}$ ) and $4.5 \%\left(3 \mathrm{mg} \mathrm{mL}^{-1}\right)$ after 12 hours. During the dissolution studies, it was observed that there was negligible degradation of CP from hydrodynamically balanced capsule formulations at both pHs. This could be attributed to the entrapment of $\mathrm{CP}$ in the gel network, which prevented the drug from direct contact with dissolution medium and it was slowly released. As CP degradation from hydrodynamically balanced capsule formulations was almost the same at both $\mathrm{pHs}$, it was decided to carry out drug release studies in $0.1 \mathrm{~mol} \mathrm{~L}^{-1} \mathrm{HCl}$ (Table II).

\section{In vitro buoyancy studies and in vitro drug release studies}

For efficient buoyancy, polymer swelling is vital. Further, there must be a balance between swelling and water uptake $(12,13)$. In our case, the swelling of LMCH resulted in an increase in bulk volume. The air entrapped in swollen chitosan maintains the density lower than unity, which ultimately confers buoyancy to the dosage form.

Table II. In vitro characteristics of various HBS formulations

\begin{tabular}{cccc}
\hline $\begin{array}{c}\text { Formulation } \\
\text { code }\end{array}$ & $\begin{array}{c}\text { Drug concentration } \\
\text { uniformity }(\%)^{\mathrm{a}}\end{array}$ & Drug release $(\%)^{\mathrm{a}}$ & $\begin{array}{c}\text { Drug remaining in the } \\
\text { gel matrix }(\%)^{\mathrm{a}}\end{array}$ \\
\hline F1 & $99.9 \pm 1.4$ & $88.9 \pm 4.4$ & $10.2 \pm 1.0$ \\
F2 & $100.2 \pm 1.8$ & $99.8 \pm 1.8$ & $\mathrm{ND}$ \\
F3 & $99.6 \pm 1.7$ & $91.3 \pm 3.5$ & $7.6 \pm 0.8$ \\
F4 & $99.4 \pm 1.6$ & $80.8 \pm 4.1$ & $17.2 \pm 1.1$ \\
F5 & $99.5 \pm 1.3$ & $76.7 \pm 4.3$ & $21.6 \pm 0.9$ \\
F6 & $98.9 \pm 1.4$ & $96.1 \pm 3.1$ & $3.1 \pm 0.3$ \\
F7 & $99.6 \pm 1.3$ & $97.7 \pm 2.1$ & $1.2 \pm 0.1$ \\
F8 & $102.1 \pm 1.3$ & $100.3 \pm 1.9$ & $\mathrm{ND}$ \\
F9 & $100.5 \pm 1.4$ & $99.8 \pm 2.2$ & $\mathrm{ND}$ \\
\hline
\end{tabular}

a All determinations were carried out in triplicate, mean \pm SD.

$\mathrm{ND}$ - not detected 
A. Verma et al: Low molecular mass chitosan as carrier for a hydrodynamically balanced system for sustained delivery of ciprofloxacin hydrochloride, Acta Pharm. 62 (2012) 237-250.

Table III. In vitro floating characteristics of HBS formulations

\begin{tabular}{cc}
\hline Formulation code & Floatation time $(\mathrm{h})$ \\
\hline F1 & remained floating for more than $12 \mathrm{~h}$ \\
F2 & 8 \\
F3 & remained floating for more than $12 \mathrm{~h}$ \\
F4 & remained floating for more than $12 \mathrm{~h}$ \\
F5 & remained floating for more than $12 \mathrm{~h}$ \\
F6 & 9 \\
F7 & 3 (gel bursts apart) \\
F8 & 8 \\
F9 & 11 \\
\hline
\end{tabular}

It was observed from the in vitro buoyancy studies that single-unit hydrodynamically balanced capsule formulations containing $\mathrm{LMCH}$ alone (F1 and F2) or in combination with XG (F3, F4, F5 and F6) and EC (F7 and F9) and in one instance EC alone (F8) exhibited immediate buoyancy when placed in $0.1 \mathrm{~mol} \mathrm{~L}^{-1} \mathrm{HCl}$ with floatation time ranged from 3-12 hours (Table III).

Fig. 3 illustrates the release profile of CP-loaded hydrodynamically balanced capsule formulations. No lag time was observed in any of the formulations studied. The in vitro release studies carried out in triplicate in $0.1 \mathrm{~mol} \mathrm{~L}^{-1} \mathrm{HCl}$ revealed that, with the exception of F7 where about $90 \% \mathrm{CP}$ was released at the end of the first hour, all formulations remained buoyant and capable of sustaining the drug release from hydrodynamically balanced capsule formulations even though the solubility of $\mathrm{CP}$ in dissolution medium was very high. Formulation F1 released CP slowly in $0.1 \mathrm{~mol} \mathrm{~L}-1 \mathrm{HCl}$. About $6 \%$ $\mathrm{CP}$ was released one hour after exposure to the dissolution medium and about $90 \% \mathrm{CP}$

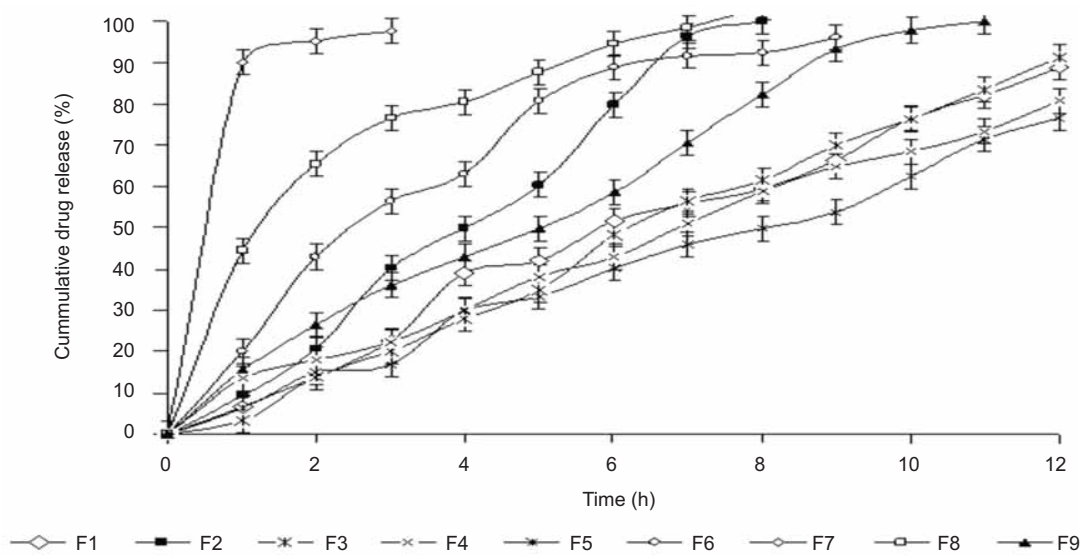

Fig. 3. \% Cumulative drug release profiles (mean $\pm \mathrm{SD}, n=3$ ) from various formulations. 
A. Verma et al.: Low molecular mass chitosan as carrier for a hydrodynamically balanced system for sustained delivery of ciprofloxacin hydrochloride, Acta Pharm. 62 (2012) 237-250.

was released from the formulation by the end of the twelfth hour. With increase in CP loading (F2), it was expected that the matrix of the gel formed would become more relaxed allowing easy solvent penetration leading to enhanced drug diffusion but the release profiles were virtually identical despite the change in CP loading.

It was observed that the disruption of capsule shell began as soon as it was placed in dissolution medium but its complete disruption occurred in about 15 min. During this period, the CP release was found to be negligible $(<0.1 \%)$ but as the dissolution medium penetrated through the disrupted capsule shell, the outer layer of polymer matrix hydrated to form the gel and $\mathrm{CP}$ began to diffuse out of the polymer matrix. As the time progressed, the dissolution medium penetrated deep into the matrix and the $\mathrm{CP}$ release was accelerated (from $15 \% \mathrm{~F} 1$; from $21 \% \mathrm{~F} 2$, after the second hour) from the matrix.

In formulation F7, EC was added as a buoyancy imparting agent because of its very low bulk density and hydrophobic nature. Without EC, the formulation sank within 15 min. However, formulation F7 could not float for more than three hours. The poor buoyancy could be attributed to the weak gel network formed by the low concentration of $\mathrm{LMCH}$ in the formulation that could not hold EC particles in the gel network.

\section{Drug concentration uniformity}

The drug concentration uniformity (Table II) of various hydrodynamically balanced capsule formulations for CP varied between 98.9 and $102.1 \%$. It could be attributed to the little difference between drug densities [bulk density after 50 taps $\left(V_{50}\right)=0.37 \mathrm{~g} \mathrm{~cm}^{-3}$ ] and polymer [bulk density $\left(V_{50}\right): \mathrm{LMCH}=0.32 \mathrm{~g} \mathrm{~cm}^{-3}, \mathrm{XG}=0.53 \mathrm{~g} \mathrm{~cm}^{-3}, \mathrm{EC}=0.33 \mathrm{~g}$ $\mathrm{cm}^{-3}$ ], selected drug/polymer (s) ratios, mixing efficiency time.

\section{Effect of release modifiers}

In order to determine the effect of incorporation of a hydrophilic or hydrophobic polymer on drug release, a hydrocolloid like XG and a water insoluble cellulose derivative, EC, were selected. In case of formulations F3, F4 and F5 (Table I), a progressive amount of XG $(10,20$ and $30 \%, m / m$, of LMCH) was intimately blended with LMCH and $\mathrm{CP}$. The reason for incorporating $\mathrm{XG}$ into hydrodynamically balanced capsule formulations was based on the fact that when the encapsulated LMCH-XG matrix containing CP was exposed to dissolution media, imbibition of the dissolution medium into it initiated the formation of a gel layer around the polymer matrix. Now the diffusion of dissolved drug through this gel layer was the determining factor in the improvement of the dissolution rate. It has been reported that increased viscosity results in a corresponding decrease in the drug release rate (14). Therefore, significant retardation of CP release from these HBS formulations was presumed. However, unexpectedly, release of CP from formulations F3 and F4 was not significantly different from that of formulation F1. About 8 and $6 \% \mathrm{CP}$, respectively, had been released at the end of the first hour and up to $90 \% \mathrm{CP}$ was released from both formulations (F3 and F4) by the end of the twelfth hour. The release profiles (F3 and F4) were virtually identical to formulation F1. In case of formulations F3 and F4, it seems that the increase in viscosity of formulations (gel formation during dissolution) was not sufficient to bring about a significant decrease in CP release from the gelled matrix. On the other hand, a significant difference $(p<0.05)$ in 
A. Verma et al.: Low molecular mass chitosan as carrier for a hydrodynamically balanced system for sustained delivery of ciprofloxacin hydrochloride, Acta Pharm. 62 (2012) 237-250.

$\mathrm{CP}$ release was observed between formulation F5 (gel layer remained floating in dissolution medium even after 12 hours) and F1. About 3 and $76 \% \mathrm{CP}$ had been released from formulation F5 at the end of the first and twelfth hour, respectively. One of the reasons for the decreased drug release rate from formulation F5 could be attributed to the increased viscosity of the gelled polymeric system. For this purpose, we carried out viscosity measurement studies to study the effect of the gelled polymeric matrix on CP release. It was observed that when solutions of $\mathrm{LMCH}$ and $X \mathrm{XG}$ in $0.1 \mathrm{~mol} \mathrm{~L}^{-1} \mathrm{HCl}$ were mixed, the final solution containing $1 \%(\mathrm{~m} / \mathrm{V}) \mathrm{LMCH}$ and $0.3 \%(\mathrm{~m} / \mathrm{V}) \mathrm{XG}$ became slightly hazy with evidence of precipitation and therefore its viscosity could not be measured accurately. This change in the appearance of the solution could be attributed to the polyelectrolyte complex (PEC) formation between $\mathrm{LMCH}$ and $\mathrm{XG}$, which was further supported by liquid state interaction studies. Charge interaction between cationic LMCH in acidic medium and anionic XG (LMCH:XG ratio 3.33:1) resulted in the formation of PEC, which resulted in strong gel formation capable of sustained release of CP. In case of formulation F6, our experimental results indicated that the addition of XG could not compensate for high CP concentration as about 13 and $96 \% \mathrm{CP}$ was released at the end of the first and ninth hour resp., from formulation F6. This was not significantly different from F2 (9 and $99 \% \mathrm{CP}$ at the end of the first and eighth hour). This could be attributed to the formation of a comparatively relaxed gel matrix, which allowed easy solvent penetration, leading to enhanced drug diffusion.

In formulation F7, the polymer matrix was composed of equal amounts of $\mathrm{LMCH}$ and EC (50\%, $m / m$, each). The CP release from formulation F7 was found to be very fast with about $90 \% \mathrm{CP}$ released at the end of the first hour and almost all the $\mathrm{CP}$ released at the end of three hours. The possible reason for this burst release of the drug could be attributed to the low concentration of $\mathrm{LMCH}$ that could not form a strong gel network.

In formulation $\mathrm{F} 8, \mathrm{LMCH}$ was completely replaced with EC. The $\mathrm{CP}$ release from formulation F8 was significantly retarded compared to F7 with approximately $44 \%$ of $\mathrm{CP}$ released within the first hour and the entire drug was released in eight hours (F8 was significantly different from F7, $p=0.05$ ). The explanation could be that, because of large differences in density between $\mathrm{CP}$ and EC, the $\mathrm{CP}$ seemed to be coated on the low density EC particles. When the formulation was exposed to the dissolution medium, it acted as a raft and only the $\mathrm{CP}$ present on the exposed surface went into the dissolution medium. Further release of CP from the polymer matrix was delayed due to poor penetration of dissolution medium into hydrophobic polymer matrix and thus retarded $\mathrm{CP}$ release from the formulation.

In formulation F9, the purpose of incorporating EC was to modify the hydrophilicity of the polymer matrix. Drug release from formulation F9 was significantly sustained compared to formulation F2 $(p<0.05)$ and F6 $(p=0.0008)$. About $15 \%$ CP was released by the end of the first hour, and almost all the CP had been released by the end of the eleventh hour. Addition of EC to formulation F9 confered a certain degree of hydrophobicity to the formulation, which resulted in a significant retardation of drug release.

\section{Mechanism of drug release}

The in vitro release pattern of various formulations was analyzed by fitting the dissolution data into various kinetic models (Table IV). It was observed that for formula- 
A. Verma et al:: Low molecular mass chitosan as carrier for a hydrodynamically balanced system for sustained delivery of ciprofloxacin hydrochloride, Acta Pharm. 62 (2012) 237-250.

Table IV. Drug release kinetics of HBS formulations of ciprofloxacin hydrochloride

\begin{tabular}{|c|c|c|c|c|c|}
\hline \multirow{2}{*}{$\begin{array}{l}\text { Formulation } \\
\text { code }\end{array}$} & \multicolumn{4}{|c|}{$R^{2}$} & \multirow{2}{*}{$n$} \\
\hline & Zero order & First order & Higuchi & Korsmeyer-Peppas & \\
\hline $\mathrm{F} 1$ & 0.9869 & 0.7231 & 0.9381 & 0.9815 & 1.03 \\
\hline F2 & 0.9909 & 0.7651 & 0.8925 & 0.9895 & 1.17 \\
\hline F3 & 0.9945 & 0.8004 & 0.9129 & 0.9798 & 1.25 \\
\hline F4 & 0.9926 & 0.6811 & 0.9441 & 0.9677 & 0.77 \\
\hline F5 & 0.9989 & 0.7371 & 0.9251 & 0.9847 & 0.97 \\
\hline F6 & 0.9053 & 0.5604 & 0.9724 & 0.9668 & 0.84 \\
\hline F7 & 0.8855 & 0.9819 & 0.8842 & 0.9961 & 0.39 \\
\hline F8 & 0.7814 & 0.4066 & 0.9697 & 0.9764 & 0.51 \\
\hline F9 & 0.9932 & 0.6602 & 0.9426 & 0.9988 & 0.73 \\
\hline
\end{tabular}

tions F1, F2, F3, F4, F5 and F9, the $R^{2}$ values were higher when fitted to a zero-order equation, which indicated a zero-order release from these formulations. Formulations F6 and F8 followed the Higuchi release pattern, whereas formulation F7 followed first-order release.

Drug diffusion through most types of polymeric systems is often best described by Fickian diffusion, but in addition to diffusion, other processes are also important. There is also relaxation of polymer chains that influences the drug release mechanisms (non-Fickian or anomalous diffusion). Release from initially dry, hydrophilic glassy polymers, which swell when added to water and become rubbery, shows anomalous diffusion as a result of the arrangement of macromolecular chains. The thermodynamic state of the polymer and the penetrant concentration are responsible for the different types of diffusion. A third class of diffusion is the case II diffusion ( $n=1$ for zero order) which is a special case of non-Fickian diffusion. For the values of $n$ higher than 1 , the mechanism of drug release is regarded as super case-II transport. Regarding the $n$ values calculated for the studied formulations, in most cases (F4, F5, F6, F8 and F9) a non-Fickian mechanism was found to be predominant, which indicated that the $\mathrm{CP}$ release was dependent on its solubility in the dissolution medium and swelling and erosion of the polymer matrix. Formulation F7 followed the Fickian release pattern, which suggested that the governing factor for drug transport in the gels was ordinary diffusion. Formulation F1 followed the case II transport mechanism. Case II transport mechanism suggests that the dominant mechanism for drug transport is due to polymer relaxation as the gels swells. On the other hand, formulations F2 and F3 followed the super Case II transport mechanism, which is characterized by acceleration in solvent penetration into the polymer matrix. The speed of solvent diffusion in the matrix is much greater than the swelling, with this being the determining factor in the drug release (15). 
A. Verma et al: Low molecular mass chitosan as carrier for a hydrodynamically balanced system for sustained delivery of ciprofloxacin hydrochloride, Acta Pharm. 62 (2012) 237-250.

\section{CONCLUSIONS}

In order to get more insight into the suitability of chitosan as a carrier for the stomach specific drug delivery system, we have made an attempt to study the feasibility of low molecular weight chitosan alone or in combination with another biocompatible polymer, xanthan gum. The prepared hydrodynamically balanced capsule formulations exhibited excellent in vitro buoyancy and were capable of sustaining the release of model drug CP. Considering the experimental data, it may be concluded that LMCH alone, or in combination with XG, is a potential polymeric carrier suitable for the development of a hydrodynamically balanced system for the stomach specific delivery of drugs with an absorption window in the upper GIT.

Acknowledgements. - The authors are thankful to R. M. Dubey, Managing Director, Institute of Foreign Trade and Management, for providing facilities and an Institutional Research Grant.

\section{REFERENCES}

1. N. Bhattarai, J. Gunn and M. Zhang, Chitosan-based hydrogels for controlled, localized drug delivery, Adv. Drug Del. Rev. 62 (2010) 83-99; DOI: 10.1016/j.addr.2009.07.019.

2. E. R. Gariépy and J. C. Leroux, Chitosan: A Natural Polycation with Multiple Applications, in Polysaccharides for Drug Delivery and Pharmaceutical Applications (Eds. R. H. Marchessault, F. Ravenelle and X. X. Zhu), ACS Symposium Series, Vol. 934, Washington 2006, pp. 243-259; DOI: 10.1021/ bk-2006-0934.ch012.

3. T. W. Wong, Chitosan and its use in design of insulin delivery system, Recent Pat. Drug Del. Formul. 3 (2009) 8-25.

4. A. E. B. Yassin, A. A. Ibrahim and M. A. Abdulah, Chitosan beads as a new gastroretentive system of verapamil, Sci. Pharm. 74 (2006) 175-188.

5. S. Y. Park, K. S. Marsh and J. W. Rhim, Characteristics of different molecular weight chitosan films affected by the type of organic solvents, J. Food Sci. 67 (2002) 194-197; DOI: 10.1111/j.1365-2621.2002.tb11382.x.

6. J. Ali, S. Arora, A. Ahuja, A. K. Babbar, R. K. Sharma, R. K. Khar and S. Baboota, Formulation and development of hydrodynamically balanced system for metformin: In vitro and in vivo evaluation, Eur. J. Pharm. Biopharm. 67 (2007) 196-201; DOI: 10.1016/j.ejpb.2006.12.015.

7. United States Pharmacopoeia 27/National Formulary 22, USP Pharmacopoeial Convention, Rockville (MD) 2000.

8. D. W. A. Bourne, Pharmacokinetics, in Modern Pharmaceutics (Eds. G. S. Banker and C. T. Rhodes), $4^{\text {th }}$ ed., Marcel Dekker, New York 2002, pp. 67-92.

9. T. Higuchi, Rate of release of medicaments from ointment bases containing drugs in suspensions, J. Pharm. Sci. 50 (1961) 874-875; DOI: 10.1002/jps.2600501018.

10. R. W. Korsmeyer, R. Gurny, E. Doelker, P. Buri and N. A. Peppas, Mechanisms of solute release from porous hydrophilic polymers, Int. J. Pharm. 15 (1983) 25-35; DOI: 10.1016/0378-5173(83) 90064-9.

11. A. M. Qandil, A. A. Obaidat, M. A. Mohammed Ali, B. M. Al-Taani, B. M. Tashtoush, N. D. Al-Jbour, M. M. Al Remawi, K. A. Al-Sou'od and A. A. Badwan, Investigation of the interactions in complexes of low molecular weight chitosan with ibuprofen, J. Solution Chem. 38 (2009) 695-712; DOI: 10.1007/s10953-009-9405-4. 
A. Verma et al.: Low molecular mass chitosan as carrier for a hydrodynamically balanced system for sustained delivery of ciprofloxacin hydrochloride, Acta Pharm. 62 (2012) 237-250.

12. W. Erni and K. Held, The hydrodynamically balanced system: a novel principle of controlled drug release, Eur. Neurol. 27 (1987) 21-27; DOI: 10.1159/000116171.

13. P. R. Sheth and J. Tossounian, The hydrodynamically balanced system (Hbs $\left.{ }^{\mathrm{Tm}}\right)$ : A novel drug delivery system for oral use, Drug Dev. Ind. Pharm. 10 (1984) 313-339.

14. L. S. Wan, P. W. Heng and L. F. Wong, Relationship between swelling and drug release in a hydrophilic matrix, Drug Dev. Ind. Pharm. 19 (1993) 1201-1210; DOI: 10.3109/03639049309063012.

15. P. J. Cox, K. A. Khan, D. L. Munday and J. Sujja-areevath, Development and evaluation of a multiple-unit oral sustained release dosage form for $S(+)$-ibuprofen: preparation and release kinetics, Int. J. Pharm. 193 (1999) 73-84; DOI: 10.1016/S0378-5173(99)00320-8.

$S A \check{Z} E T A K$

\section{Kitozan male molekulske mase kao nosač hidrodinamički uravnoteženog sustava za usporenu isporuku ciprofloksacin hidroklorida}

ANURAG VERMA, ASHOK K. BANSAL, AMITAVA GHOSH i JAYANTA K. PANDIT

Zbog svoje biokompatibilnosti, biorazgradljivosti i netoksičnosti kitozan je vrlo interesantan istraživačima u području farmaceutske tehnologije. Najviše se upotrebljavao u dizajniranju različitih sustava za isporuku lijekova ali vrlo malo za sustave za specifičnu isporuku u želucu. Cilj ovog rada bio je ispitati mogućnost upotrebe kitozana male molekulske mase (LMCH) kao nosača u hidrodinamički balansiranom sustavu (HBS) za usporenu isporuku vodotopljivog lijeka ciprofloksacin hidroklorida (CP). Pripravljene su različite formulacije stvaranjem fizičke smjese lijeka i polimera u različitim omjerima, koje su potom kapsulirane u želatinske kapsule. Svi su pripravci za vrijeme cijelog eksperimenta ostali plutati u $0,01 \mathrm{~mol} \mathrm{~L}{ }^{1} \mathrm{HCl}(\mathrm{pH} 1,2)$. Ispitivan je i učinak ksantan gume $(\mathrm{XG})$ ili etilceluloze (EC) na oslobađanje lijeka. Oslobađanje lijeka nultog reda postignuto je iz formulacija koje sadrže samo LMCH ili LMCH u kombinaciji sa XG i u jednom slučaju s EC. Dobiveni rezultati pokazuju da je LMCH, sam ili u kombinaciji sa XG, izvrstan materijal za sustave za specifičnu isporuku $\mathrm{CP}$ iz hidrodinamički balansiranih kapsula.

Ključne riječi: kitozan male molekulske mase, ksantan guma, ciprofloksacin, hidrodinamički uravnotežene kapsule, oslobađanje u želucu

Department of Pharmaceutics, College of Pharmacy, IFTM, Moradabad-244001, India

Department of Pharmaceutics, Institute of Technology, Banaras Hindu University, Varanasi, India 